\title{
Construir la PAZ en Colombia desde la EDUCACIÓN ${ }^{1}$
}

\author{
Tomás Calvo Buezas \\ tcalvobuezas@yahoo.es
}

\section{Comentario}

\section{Un misionero extremeño asesinado, como símbolo pedagógico de reconciliación}

El 29 de mayo se cumplen 25 años del secuestro por parte de la güerilla colombiana del sacerdote español Javier Ciriaco Cirujano Arjona (nacido el 7 noviembre 1927 en Jaraíz de la Vera, Extremadura), apareciendo su cadáver un mes y medio más tarde torturado, apaleado, castrado, con machetazos por todo el cuerpo. El 24 de julio de 1993 fue enterrado en Jaraíz, donde descansan sus restos.

¿Porqué 25 años más tarde se quiere rememorar su cruel asesinato y servir de signo de reconciliación en el proceso de Paz de Colombia? ¿Y por qué esa Memoria viene significada como martirio por la comunidad cristiana de la Arquidiócesis de Cartagena de Indias y particularmente en la zona de los Montes de María donde vivió 30 años y murió vilmente asesinado?

La Paz se ha firmado afortunadamente en Colombia...pero firmar la paz no es construirvivir-hacer las paces. Si fueron muchos años de salvajes crímenes, odios tribales de unos y otros, se necesitan también no años, sino muchas décadas en construir la "paz". ¿y cómo? Pasito a pasito y granito de arena a granito de arena. Y esta labor de concientización y educación en la paz debe comenzar en el corazón de las personas, que es donde se originan los odios y las guerras, y por lo tanto en "donde firmarse la paz". También en esa pedagogía colectiva deben comprometer todas las instituciones políticas, religiosas, medios de comunicación, universidades, organizaciones no gubernamentales, sindicatos, partidos, artistas, pero en esta tarea de reconciliación y paz, tiene un papel crucial las instituciones educativas, universidades, colegios, y más singularmente los centros de educación primaria, e incluso de educación infantil.

\section{Un misionero constructor de Colegios en zona pobre: "Mártir de la Paz"}

En sus 30 años en los apartados y semiselváticos Montes de María, y concretamente en San Jacinto y sus caseríos cercanos no había a su llegada ningún Colegio de Secundaria y en los corregimientos y aldeas vecinas escuelas primarias. Pues el Padre Javier Cirujano construyo dos Institutos, 5 escuelas y un Colegio Técnico de música, ya que sus pobladores tienen un

${ }^{1}$ Recibido: 23/07/2018 Evaluado:28/07/2018 Aceptado:01/07/2018 
tradicional folklore muy rico con artistas gaiteros famosos. Y toda esta inmensa labor educativa y social la realizó en un ambiente de conflicto armado, de guerra civil, de guerrillas y paramilitares, sirviendo de intermediario entre las partes, lo que le hizo confiar demasiado, en que a él no le pasaría nada, porque tenía estudiantes alumnos en ambas partes, aunque eso no le impidiese fustigar incesantemente los crímenes y asesinatos de ambos lados, en sus sermones.
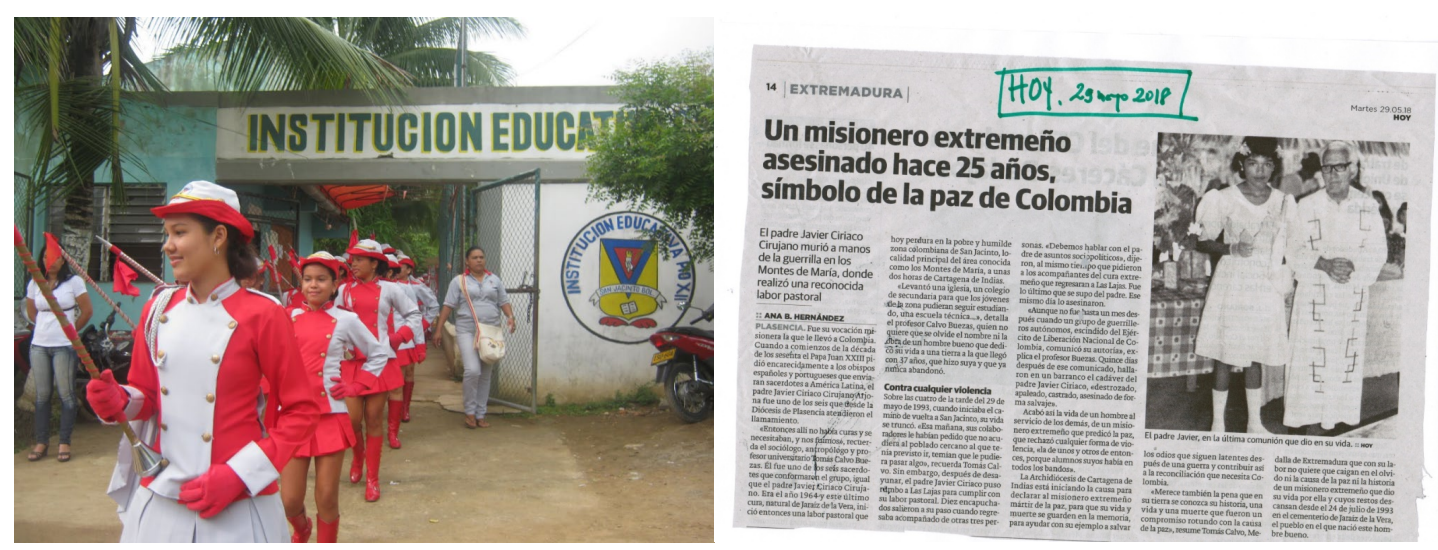

Foto de la izquierda: Desfile de chicas del Colegio Pio XII, fundado por el P. Javier Cirujano. Y a la derecha, la última foto de su vida: su última comunión el día que le secuestraron y asesinaron a su vuelta del caserio

\section{Historia de un asesinato cruel a un educador pacífico}

Así lo narra textualmente el Documento del Vicario de la Arquidiócesis de Cartagena de Indias, Padre Rafael Castillo Torres, titulado "Padre Cirujano: Memoria de un Misionero...Testimonio de un Mártir"

"E1 Padre Javier Cirujano partía de San Jacinto el 29 de mayo de 1993 hacia el corregimiento (aldea rural) de Las Lajas en el sagrado cumplimiento de su labor pastoral. Partió temprano después de tomar un ligero desayuno. En su último diálogo con Nelly, su secretaria, le dijo: "Voy a Las Lajas (caserío apartado, zona de guerrilleros) y espero regresar en la tarde, si me demoro no se deben alarmar. El domingo si no he llegado le agradezco le informe al Señor Arzobispo."

Después de realizar el Ministerio Pastoral en Las Lajas, regresó a caballo acompañado de dos profesores de la Escuela y un Señor de la vereda. En el punto denominado "Loma Colorada", a eso de las 4:00 p.m. apareció un grupo de 10 hombres encapuchados que lo retuvieron. La única explicación que dieron fue: "Debemos hablar con el padre de asuntos Socio-políticos". Y les pidieron que regresaran a Las Lajas y que por ningún motivo regresaran hacia San Jacinto. Fue lo último que se supo del Padre. Ese mismo día lo asesinaron2. 
El cinco de septiembre del año 1988 escribió a su hermana Pilar: "Si vierais la soledad de mi vida, es algo horrible y sobre todo saber que uno debe ser la respuesta para todo y para los interrogantes de uno nadie...Antes me horrorizaba cuando veía en la televisión situaciones como ésta que estamos viviendo nosotros, hoy me he vuelto insensible como mecanismo de defensa pero allá dentro lo vivo con toda intensidad..."El 4 de mayo, en su último escrito a sus familiares afirmó: "Estoy deseoso de ir para disfrutar un tramo de la existencia porque esto no es vida, es la sala de espera a un ajusticiamiento o un infierno en soledad, ni exagero, ni soy hipocondríaco. Un abrazo: Javier"

Mes y medio más tarde fue encontrado su cadáver, torturado, apaleado, castrado, con machetazos por todo el cuerpo. En San Jacinto se le hizo una despedida con la activa participación de todos los estudiantes, niños y adolescentes, un funeral en la catedral de Cartagena de Indias y el traslado de su cadáver a España, siendo enterrado en Jaraíz de la Vera (Extremadura) el día 24 de julio de 1993.

\section{Tras 60 años de guerra, firma de la Paz}

El 26 de septiembre de 2016 se firmaron en la Habana Los Acuerdos de Paz entre el Gobierno y la guerrilla de las FARC, tras cuatro años de conversaciones, y más de 50 años de guerra civil. El presidente Santos fue el principal hacedor de éste histórico acuerdo. En las elecciones presidenciales, Iván Duque, fue el vencedor el 17 de junio 2018, con el 54\% de los votos. Declaró tras su victoria: "La paz que añoramos, que reclama correcciones, tendrá correcciones para que las víctimas de verdad sean el centro del proceso y garanticemos verdad, justicia, reparación y no repetición", "Hoy somos todos amigos de construir esa paz ". Ahora bien "hacer la PAZ es casi más difícil que estar en guerra" (Editorial de El País, 20 junio 2018)

Esa gran dificultad de "construir la paz" tras tan larga y sangrienta guerra, fue también la impresión que tuve tras visitar, hace 4 años, Colombia y San Jacinto, conversando largamente con algunas de sus gentes. Comprobé los sentimientos de odios encontrados, con ánimos emotivos de venganza, miedos y recelos de todos contra todos, siendo necesario un paciente y largo proco de sensibilización por la paz y concordia, particularmente ente los niños y adolescentes.

\section{¿Por qué recordar ahora hechos sangrientos de una guerra fratricida?}

¿Para continuar la guerra en nuestros corazones con la reminiscencia dolorosa de heridas de muerte a nuestros familiares y seres queridos? NO y NO. Es honorable y pedagógico hacer memoria de seres buenos y pacíficos, que nunca mataron a nadie, sino que por el contrario clamaron contra toda clase de asesinatos de ambos bandos; y que por condenar la violencia de guerrilleros y paramilitares, fueron víctimas de la barbarie y de la guerra. Estos hombres pacíficos son la mejor semilla para la reconciliación y para la construcción de la paz, En los Montes de María, donde se desarrolló la labor pastoral, educativa y social del padre Javier Ciriaco Cirujano, en que la guerra fue intensa y cruenta, los fusiles están rotos, pero las mentes y los corazones de ancianos, mayores y niños continúan llenos de odios fratricidas, que rezuman sangre simbólica y ansias de venganza. Y precisamente en esa zona oscura de las personas humanas, y a la vez decisiva en sus comportamientos externos, es donde debe realizarse la paciente y laboriosa tarea pedagógica de la reconciliación colectiva y de la 
concordia para una convivencia democrática, tolerante con las diferencias ideológica, pero solidaria en los objetivos comunes de bienestar cívico y democrático, en una exigencia estricta de justicia social, que es la condición de la paz. Y esto hay que inculcarles a los niños desde pequeñitos.

\section{No nacemos violentos, pero tampoco nacemos pacíficos: "nos hacemos"}

Es falsa la aseveración educativa de J.J. Rousseau, de que "nacemos buenos y la sociedad nos hace malos”. ¡Perverso error! Debemos insistir en que no nacemos violentos, asesinos, racistas, malos, pero "tampoco nacemos pacíficos, buenos, solidarios, justos, nos hacemos pacíficos, solidarios y por lo tanto es necesario educarnos, desde la familia, pero principalmente en los Colegios y por los medios de comunicación, en los valores de la cultura de la paz. Hay que tomar conciencia de que cuestiones vitales, como el cese de la violencia armada y de la paz, no es cosa sólo de políticos y militares, sino principalmente de la sociedad civil, de sus instituciones educativas y religiosas, de la opinión pública, y por supuesto de sus escuelas, desde la educación infantil. Recordemos que "no nacemos pacíficos, nos hacemos". De ahí el papel crucial que ha de prestarse a la pedagogía de la cultura de la Paz, como insistentemente reclama la UNESCO.

Deseo terminar estas reflexiones con los mismos sentimientos y palabras escritas por mí en la prensa extremeña (24 julio 2013) en IN MEMORIAM de los 20 años de su cruel asesinato:

"Ansiamos, querido Javier Ciriaco, que tu sangre, y la de tantos inocentes, asesinados por guerrilleros, militares y crueles paramilitares, sea fecunda semilla de concordia humana y mensaje pedagógico de Paz. ¡Ha llegado la hora convertir las armas en azadones de labranza para los sufridos campesinos y lograr la Paz en la preclara Colombia!" 